\title{
Research Methods and Statistics
}




\section{INTRODUCTORY PSYCHOLOGY}

This series of titles is aimed at psychology students in sixth forms and further education colleges and at those wishing to obtain an overview of psychology. The books are easy to use, with comprehensive notes written in coherent language; clear flagging of key concepts; relevant and interesting illustrations; well-defined objectives and further reading sections to each chapter, and self-assessment questions at regular intervals throughout the text.

\section{Published}

INDIVIDUAL DIFFERENCES

Ann Birch and Sheila Hayward

DEVELOPMENTAL PSYCHOLOGY

Ann Birch and Tony Malim

BIOPSYCHOLOGY

Sheila Hayward

COGNITIVE PROCESSES

Tony Malim

COMPARATIVE PSYCHOLOGY

Tony Malim, Ann Birch and Sheila Hayward

RESEARCH METHODS AND STATISTICS

Tony Malim and Ann Birch

SOCIAL PSYCHOLOGY

Tony Malim and Ann Birch

PERSPECTIVES IN PSYCHOLOGY

Tony Malim, Ann Birch and Alison Wadeley

\section{Series Standing Order}

If you would like to receive future titles in this series as they are published, you can make use of our standing order facility. To place a standing order please contact your bookseller or, in case of difficulty, write to us at the address below with your name and address and the name of the series. Please state with which title you wish to begin your standing order. (If you live outside the United Kingdom we may not have the rights for your area, in which case we will forward your order to the publisher concerned.)

Customer Services Department, Macmillan Distribution Ltd Houndmills, Basingstoke, Hampshire RG21 6XS, England 


\section{RESEARCH \\ METHODS AND \\ STATISTICS}

Tony Malim and Ann Birch 


\section{2}

(C) Tony Malim and Ann Birch 1997

All rights reserved. No reproduction, copy or transmission of this publication may be made without written permission.

No paragraph of this publication may be reproduced, copied or transmitted save with written permission or in accordance with the provisions of the Copyright, Designs and Patents Act 1988 , or under the terms of any licence permitting limited copying issued by the Copyright Licensing Agency, 90 Tottenham Court Road, London W1P 9HE.

Any person who does any unauthorised act in relation to this publication may be liable to criminal prosecution and civil claims for damages.

First published 1997 by

MACMILLAN PRESS LTD

Houndmills, Basingstoke, Hampshire RG21 6XS

and London

Companies and representatives

throughout the world

ISBN 978-0-333-64439-3 ISBN 978-1-349-13865-4 (eBook)

DOI 10.1007/978-1-349-13865-4

A catalogue record for this book is available from the British Library.

$\begin{array}{llllllllll}10 & 9 & 8 & 7 & 6 & 5 & 4 & 3 & 2 & 1\end{array}$

$\begin{array}{llllllllll}06 & 05 & 04 & 03 & 02 & 01 & 00 & 99 & 98 & 97\end{array}$

Editing and origination by Aardvark Editorial, Mendham, Suffolk

Cartoons by Sally Artz 


\section{Contents}

List of Figures vii

Preface ix

Acknowledgements xi

1 Introduction 1

I Introducing some concepts and terms used in statistics and research

II Ethical questions in relation to research 11

2 Research Methods 17

I Experiment 17

II Experimental design and the control of variables

III Observation, survey, case study and interview techniques $\quad 31$

IV Correlational designs $\quad 42$

V Some further important considerations $\quad 46$ in research

3 Presenting the Results 55

I Descriptive statistics $\quad 59$

II Statistical inference and significance 81

III Correlation 93 
vi Contents

4 Statistical Tests 107

1 Non-parametric tests $\quad 107$

II Parametric tests 124

5 Interpretation and Presentation of Research 135

I Interpretation and background to research 135

II Writing research reports 142

6 Some Projects 153

I Experimental projects 153

II Observational studies $\quad 157$

III Correlational studies 164

Appendices 169

I Some basic mathematical rules 169

II Do-it-yourself psychology equipment 173

III Statistical tables 179

Bibliography 192

Index 195 


\section{List of Figures}

3.1 Table of raw scores showing number of nonsense syllables correctly recalled

3.2 Frequency table showing number of males and females scoring higher than 10 in a memorising task

3.3 Bar chart showing mean number of nonsense syllables correctly recalled

3.4 Two examples of pie charts

3.5 Frequency distribution table containing data from Figure 3.1

3.6 Histograms showing the frequency of scores of participants in Conditions A (with the aid) and B (without the aid) of the memory experiment

3.7 Frequency polygon of the scores from Conditions A (with the aid) and B (without the aid) in the memory experiment

3.8 A normal distribution showing the frequency of IQ scores in a sample of 500 people

3.9 Skewed distributions

3.10 Histograms illustrating large and small standard deviations

3.11 The standard deviation and the normal distribution

3.12 Normal distribution showing the heights of the Martian population

3.13 Probabilities expressed as ratios, percentages and decimals

3.14 Finding statistical significance

3.15 Curvilinear relationships 
3.16 Arched and U-shaped relationships

3.17 An outlier relative to a linear relationship

3.18 Tests of significance A. Tests of difference

B. Tests of correlation

4.1 Data for Sign test: number of correct spellings before and after playing Scrabble

4.2 Data for Wilcoxon Signed Ranks test: perception of the Müller-Lyer illusion in horizontal and vertical positions

4.3 Data for Mann-Whitney U test: number of incidents of truancy occurring in two schools

4.4 Data for Chi-Squared $\left(\chi^{2}\right)$ test: psychology 'A' level grades in two colleges

4.5 Data for Spearman's rho ( $\rho)$ test: scores from an IQ test and a test of cognitive style

4.6 Data for a related t-test: a comparison of the time taken to sort cards into two and into four piles

4.7 Data for an independent t-test: a comparison of times taken to sort cards into two and into four piles

4.8 Example of a Pearson's Product Moment correlation: nervous disposition (as measured by EPI) and absence from school

5.1 The hypothetico-deductive model for scientific research

6.1 Logarithms to base 2 for numbers between 1 and 99

6.2 Flow chart of decisions to be taken in planning a project

6.3 An explanation of the Müller-Lyer effect (after Gregory, 1968)

6.4 Reaction time in secs and fall in $\mathrm{cm}$

Appendix Figures

A Card for Müller-Lyer apparatus

B Sleeve with arrow

C Slide

D Completed Müller-Lyer apparatus

E Completed mirror drawing box 


\section{Preface}

Research Methods and Statistics is the final volume in the Introductory Psychology series, and its aims are similar to those of the other volumes in the series. Chapters 1 and 2 provide an introduction and an overview of some of the methods used in psychological research, highlighting the advantages and limitations of each. From Chapter 3 onwards, it becomes very much a workbook. Chapter 3 deals with the use of statistics in psychology to describe and to make inferences about data obtained through observations, and Chapter 4 is devoted to statistical testing. In Chapter 5, attention is paid to the way in which the results of research are interpreted and presented. Finally, in Chapter 6, several possible projects are outlined. Appendices include some very basic mathematical rules for those who are less familiar with the use of figures, guidance in making some do-it-yourself equipment which the authors have found useful, and some statistical tables for use in conjunction with the statistical procedures in Chapter 4.

The intention is that the book will provide practical help with the course work element of ' $A$ ' and 'AS' level syllabuses and the Research Methods modules. As in the other books in the series, each chapter begins with some objectives to be met, and at the end of each section there are self-assessment questions to help independent students test their understanding of the section. Readers are advised to work carefully through the text one section at a time before considering the self-assessment questions 


\section{Preface}

at the end of it. After further reading or study, the questions may be re-examined.

The book focuses primarily upon GCE ' $A$ ' and 'AS' levels and GCSE. However, it should prove useful to any one encountering psychology for the first time or indeed any students who need to use research methods and statistics. This might include perhaps biologists and students in other related disciplines. Students on university courses may find the contents valuable, as may those on BTEC/GNVQ courses, nurses, midwives and teachers. The authors hope that you will find the book both useful and enjoyable.

Tony Malim

Ann Birch 


\section{Acknowledgements}

Permission has been granted in relation to the following:

Tables A, B, C, D, E, F and J are reproduced from J. Beer (1982) Experiments in Psychology published by Weidenfeld and Nicolson

Table I is reproduced from F. Clegg (1982) Simple Statistics published by Cambridge University Press

Tables G and H are reproduced from J.G. Snodgrass (1978) The Numbers Game: Statistics for Psychology published by Oxford University Press

The authors would like once again to thank Sally Artz for the cartoons which appear at the beginning of each chapter. 


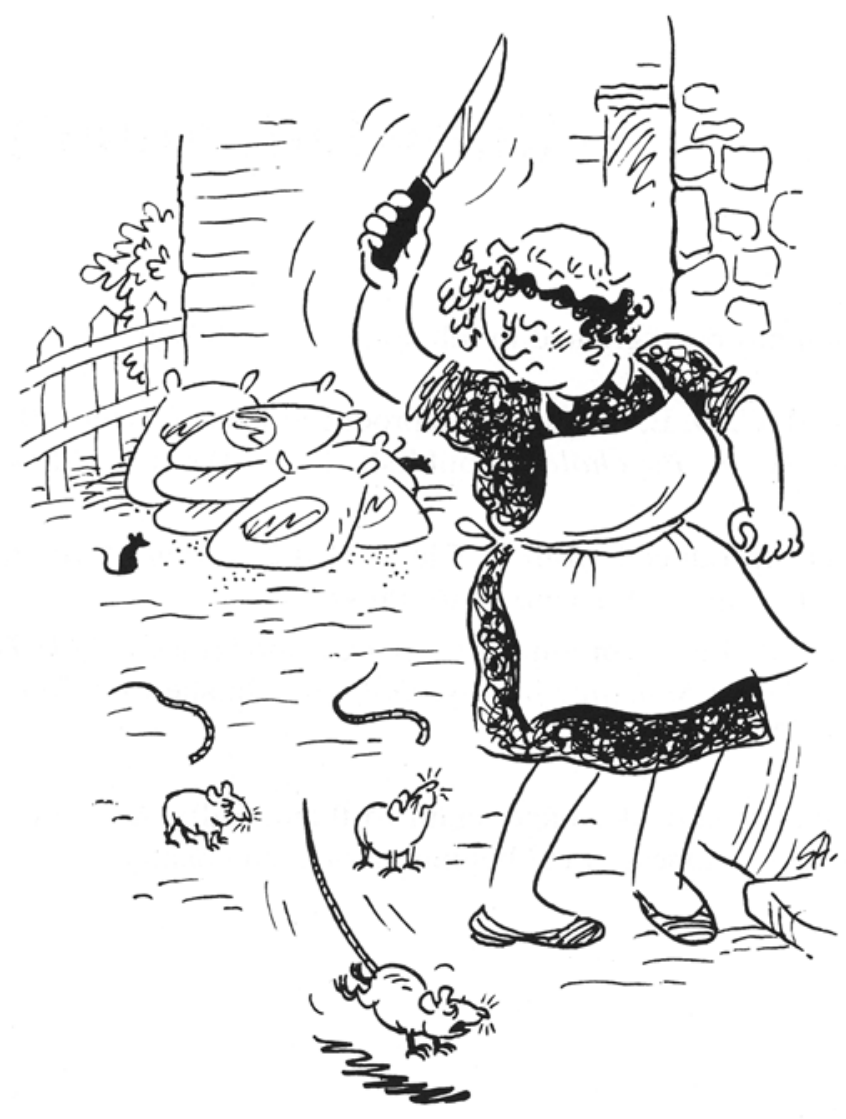

Personally, Ind be happy with a one-tailed hypothesis! 